\title{
Estimation, modelling and conservation of vertebrate populations using marked individuals
}

\author{
Michael Schaub $\cdot$ William L. Kendall
}

Received: 5 July 2011 / Accepted: 25 July 2011/Published online: 12 August 2011

(C) Dt. Ornithologen-Gesellschaft e.V. 2011

The analysis of data on marked individuals to estimate different population parameters is nowadays only seriously possible if the observation process (or data sampling process) is modelled separately from the ecological process. This requires sophisticated statistical methods. Regular conferences organised by EURING (called EURING analytical meetings) have contributed much to the development of such methods. The 9th EURING analytical meeting was held from 14 to 20 September 2009 in Pescara (Italy) and hosted by the "Istituto Superiore per la Protezione e la Ricerca Ambientale" (ISPRA). It was coupled with the EURING general assembly, where the representatives of the national ringing offices of Europe met, and thus offered the possibility to share ideas between scientists and applicants. Of particular interest for this endeavour was the wildlife session (chaired by Fernando Spina) that took place between the two events and which consisted of three review presentations about integrated monitoring, dynamics of exploited populations and adaptive management.

The main title of the analytical meeting was "Estimation, modelling and conservation of vertebrate populations using marked individuals". It highlights that the general goal of the meeting was to push forward the study and management of animal populations on three fronts: better design of studies of marked individuals or their analogs, improved approaches to modelling populations from analysis of marked individuals, and more robust conservation

M. Schaub $(\bowtie)$

Swiss Ornithological Institute, 6204 Sempach, Switzerland e-mail: michael.schaub@vogelwarte.ch

W. L. Kendall

USGS Colorado Cooperative Fish and Wildlife Research Unit, Colorado State University, Fort Collins, USA decisions resulting from such analysis. We organised the meeting basically in the same way as the past meetings, i.e. sessions were not in parallel and each was chaired by two appointed persons. As far as possible, we tried to engage one statistician and one biologist as chairs of a session. The program consisted of nine ordinary sessions, a poster session (chaired by Res Altwegg and Morten Frederiksen), a short course (Evan Cooch) and a software session (Rémi Choquet, Jim Hines). The topics of the ordinary session were defined based on discussions at the previous meeting in Dunedin (2007). As the main focus of the conference was the presentation of new or advanced methods that serve to estimate population parameters from data on marked individuals, the sessions were fairly technical. They covered "Model diagnostics" (David Fletcher, Roger Pradel), "Decision analysis" (Clint Moore, Richard Barker), "Study design" (Paul Doherty, Bill Link), "Statespace modelling" (Byron Morgan, Marc Kéry), "Spatial CMR modelling" (Andy Royle, Charles Francis), "Uncertain states and covariates" (Olivier Gimenez, Darryl MacKenzie), "Disease ecology” (Jim Nichols, Steven Baillie) and "Modelling individual variation" (Jay Rotella, Emanuelle Cam). A further session was an "Open forum" (David Thompson, Jean-Dominique Lebreton), which was the place for contributed papers that did not fit within the other predefined sessions. We developed this session in order to ensure that emerging issues in the fast moving field would also be covered. In each session, there were 3-7 talks, one being an invited keynote talk, the others being contributed papers. The selected presentations were not restricted to birds as in most previous EURING analytical meetings; however, all of them were meant to present methods that could also be applied in bird studies.

The Proceedings appear as a special issue in the Journal of Ornithology and the session chairs acted as editors for 
the papers within their sessions. We encouraged all speakers of the ordinary sessions to submit a manuscript, but not all of them did so. Nevertheless, the Proceedings contain numerous and important papers, including all keynote papers. These are usually written in the style of a review and thus are very useful in presenting the state of the art.

We would like to thank all people who helped with the organisation of the meeting and the completion of the Proceedings. We are grateful to Fernando Spina and his staff for organising a perfect meeting with delicious food and wine, and an interesting excursion to the Abruzzo mountains, to Evan Cooch for maintaining the webpage, to Franz Bairlein for the opportunity to publish the Proceedings in the Journal of Ornithology, to Steven Baillie (chair of the EURING board) for his help with the organisation, to all session chairs and to all speakers. Financial support was provided by the Amministrazione Provinciale di Pescara, by the Riserva Naturale e Oasi WWF Gole del SagittarioComune di Anversa degli Abruzzi, and by ISPRA through its staff of the Italian Ringing Centre and through the coverage of the printing costs of the volume of the Proceedings. 